\title{
Neurocognitive Aspects of Tourette Syndrome and Related Disorders
}

\author{
Marc E. Lavoie and Kieron P. O'Connor \\ Cognitive and Social Psychophysiology Laboratory, \\ FRSQ Research Team on Obsessive-Compulsive Spectrum, \\ Fernand-Seguin Research Center of the Louis-H Lafontaine Hospital, \\ Department of Psychiatry, \\ University of Montreal, Québec, \\ Canada
}

\section{Introduction}

\subsection{The challenge of characterizing Gilles de la Tourette Syndrome}

One of the top priorities, for current research in Gilles de la Tourette Syndrome (GTS), is to disentangle the intricate interactions between regions of the frontal cortex and the basal ganglia. This approach will reveal how these interactions act in concert to regulate motor, emotional, and cognitive action plans (Keen-Kim \& Freimer, 2006; Leckman, 2002; State, 2011). Another key issue is the understanding of these brain mechanisms with GTS in the presence of obsessive-compulsive disorders (OCD) (Gaze, Kepley, \& Walkup, 2006). The heuristic value of our proposed approach resides in the fact that cognitive and cerebral functions are two salient features easily quantified with non invasive protocols. As proposed by Swain et al., (Swain, Scahill, Lombroso, King, \& Leckman, 2007) "a determined effort to explore the electrophysiology of this disorder using EEG/MEG recordings is our next best step". We will first review the current state of the literature regarding specific cerebral structures underlying GTS symptoms. Secondly, we will expose a strategy to integrate brain imaging, electrophysiology and neuropsychology in the exploration of the GTS brain in action. Third, we will investigate clinical and phenomenological aspects of comorbidity in GTS patients. We will thus, expose a functional method based on multimodal assessments to characterize the relationship between tic expression, brain activity and different levels of cognitive processing such as motor activation, memory and emotions.

\subsection{Definition}

In 1885, Dr. Georges Gilles de la Tourette described nine patients with motor and vocal tics, some of which had echo phenomena (a tendency to repeat things said to them) and coprolalia (utterances of obscene phrases) (Gilles de la Tourette, 1885). This syndrome is currently classified in the DSM-IV-TR (APA, 2000) with disorders first diagnosed in infancy, childhood or adolescence. The essential features are the presence of simple or complex 
multiple motor tics and one or more vocal tics. Simple tics are defined as repetitive nonvoluntary contractions of functionally related groups of skeletal muscles in one or more parts of the body including blinking, cheek twitches and head or knee jerks among others (Leckman et al., 1997; Shapiro \& Shapiro, 1986). Complex tics may take the form of selfinflicted repetitive actions such as nail biting, hair pulling, head slapping, teeth grinding or tense-release hand gripping cycles. Tics appear many times a day with onset longer than a year and prior to 18 years old.

\subsection{Genetics in GTS}

Since the first systematic report of tics in the 19th century by Itard (Itard, 1825) and later by Gilles de la Tourette (Gilles de la Tourette, 1885), generational transmission of the disease was suspected. More than one century later, genetic factors in GTS remain hypothetical. A large twin study showed concordance rates that are three to four times higher for monozygotic than to dizygotic twins (Price, Leckman, Pauls, Cohen, \& Kidd, 1986). Studies investigating affected families with GTS suggests that the trait is inherited in an autosomal dominant pattern with variable expression (Eapen, Pauls, \& Robertson, 1993; Alsobrook \& Pauls, 1997). Analysis of vertical transmission patterns in families has revealed that OCD and GTS may share some underlying genetic vulnerabilities (Pauls, 1992). The pattern of comorbidity and other evidence indicates that GTS genes may be responsible for a spectrum of disorders, including OCD and Attention Deficit Hyperactivity Disorder (ADHD) even if OCD and ADHD can equally exist with their own etiologies. The inherited trait may not cause any disorder or may manifest as GTS, chronic multiple tic disorder, ADHD and/or OCD (Keen-Kim \& Freimer, 2006). In a comprehensive review, Pauls (2003), underlined that genetic factors play an important role in the manifestation of GTS and that several genes are important with some possibly having major effect; and several regions of the genome have been identified as potential locations of these susceptibility genes.

More specifically, sequencing of SLIT and TRK like family member 1 (SLITRK1), revealed a single base deletion as well as two independent occurrences of a mutation called the var321 (Abelson et al., 2005), likely associated with GTS. SLITRK1 expression was confirmed in cortical striatal circuits, which is consistent with regions implicated in GTS pathology (Stillman et al., 2009). An animal model of SLITRK1 deficiency shows altered noradrenergic function phenotype related to alpha-agonists, which are used in the treatment of Tourette syndrome (Katayama et al., 2010). However, the SLITRK1 gene expression in GTS remain under question since other research was not able to replicate these results in human (Scharf et al., 2008). Other candidate genes have been tested with mixed or equivocal results such as genes related to dopamine and serotonin transporters, glycine receptor, 5q33-q35 neuroreceptors, adrenergic receptors, methyl-CpG binding protein 2, and human leukocyte antigen (Keen-Kim \& Freimer, 2006; Pauls, 2003).

In brief, GTS is a genetically complex disorder that probably arises with multiple genes interacting with environmental components. Recent development could certainly show promises for success in finding the responsible genes and sequence variants, resulting in better targeted treatments. 


\subsection{Epidemiology and prevalence}

Depending on the sample characteristics, between $0.15 \%$ and $1.1 \%$ of all children have GTS and boys outnumber girls by at least 4:1 (Kadesjo \& Gillberg, 2000), with the most severe period of tic severity occurring at 10 years old (Leckman et al., 1998), followed by a decrease until the adult age with approximately $40 \%$ eventually becoming symptom-free (Burd et al., 2001). Although whether tics disappear or adapt in adults remains controversial (Pappert, Goetz, Louis, Blasucci, \& Leurgans, 2003). Tics are also sensitive to a number of exacerbating factors including everyday psychosocial stress, anxiety, emotional excitement, and fatigue (Findley et al., 2003). Once considered very rare, the incidence of GTS in adults is about 0.1$1 \%$ (Leckman et al., 1998). The lifetime prevalence of GTS in adults is not known, but estimates vary between $5 \%$ and $10 \%$ of the population. In a recent study, O'Connor (2005) found a self-report life-time prevalence rate of $8 \%$. Other recent estimates have placed the prevalence of GTS at 1\% and chronic tic disorders at 10\% of the population (Robertson, 2003; Robertson \& Stern, 2000).

\subsection{Secondary distress caused by tics}

Tics are rarely life-threatening except in cases where they may provoke auto-mutilation. Psychosocial distress however can be considerable and can involve secondary phobias, depressions, social anxieties and worries over self-image, and relationship problems. In our estimation of the interference of tic and habit disorders in daily activities, we found problems ranging from unemployment, marital conflict, interpersonal difficulties, employer relations, travel restrictions, problems attending social or public functions, performance worries (e.g. about driving, speaking, teaching, dancing, sport) all of which were perceived (by the affected person) to be a result of the tic habit (O'Connor, 2005; O'Connor et al., 2001). People with tics often experience low self-esteem and are (or become) hyperattentive to the judgment of others with consequent low self-satisfaction (Thibert, Day, \& Sandor, 1995).

\subsection{Comorbidity and associated disorders}

The presence of tic symptoms alone is often the exception rather than the rule (Scahill, Sukhodolsky, Williams, \& Leckman, 2005) and the expression of tics is a constituent part of a larger mosaic of collateral symptoms. Comorbidity is defined as an additional coexisting diagnosable problem distinct from the principal complaint. So, in addition to this clinical picture defined herein, GTS often appears in association with other psychopathologies, typically referred to as the "GTS+" group (Robertson, 2003). Freeman et al., (2000) established that anger control problems, sleep difficulties, coprolalia, and self-injurious behavior, reached high levels in GTS individuals with comorbidity. Large epidemiological studies also showed that the most frequent comorbidity in GTS is ADHD in children and OCD in adults, affecting each about $50 \%$ of GTS patients (Alsobrook \& Pauls, 2002; Freeman, 2007; Freeman et al., 2000). Studies are frequently compromised because of not factoring out comorbidity. There are however challenges in detecting and diagnosing comorbidities in GTS. For instance, early research (e.g., (Shapiro \& Shapiro, 1992) argued that high rates of comorbidity of GTS with OCD result from mistaking impulsion for compulsion particularly in the case of complex tics, and this may explain the wide range in prevalence estimation. Another difficulty is that the multiple forms of tics (phonic, motor, sensory, cognitive, simple, complex) can be mistaken for symptoms of other disorders. 


\subsection{Externalizing and aggressive behavior in GTS}

The challenge of characterizing GTS per se is often confounded by externalizing symptoms that superimpose on tics and there is a clear consensus on the importance of considering these symptoms. Stephens and Sandor (1999) found that conduct disorder was significantly higher in the GTS+ comorbidity group than in the GTS-only or control groups, with more problems reported in older children. These findings provide evidence that aggressive behavior observed in children with GTS may be associated with comorbidity, independently of tic severity or age. Consistently, Carter (2000) demonstrated that children with GTS+comorbidity showed more behavior problems and poorer social adaptation than children with GTS only or unaffected controls. Children with GTS only were not significantly different from controls on most measures of externalizing behaviors and social adaptation, but did exhibit more internalizing symptoms. Moreover, tic symptom severity was not associated with social, behavioral, or emotional functioning among children with GTS, even after stratifying by medication status. These findings suggest that much of the social and behavioral dysfunction in children with GTS could be ADHD or OCD-specific and children with GTS alone may have a very different social-emotional profile than those with GTS+comorbidity. The impact of such comorbidity is especially evident in children where the co-occurrence of GTS with OCD, particularly in the presence of ADHD, increase the likelihood of explosive behavior (Budman, Bruun, Park, \& Olson, 1998; Budman, Rockmore, Stokes, \& Sossin, 2003). In explosive behavior, the child, for no apparent reason and for a brief period, flies into a state of seemingly uncontrollable, sometimes aggressive, anger, only to resume a normal demeanor a few minutes later. But rage and explosive behavior may be an emotional tic, similar in form and onset to motor tics and hence form part of GTS (Budman, Bruun, Park, Lesser, \& Olson, 2000). The difficulty for diagnosis is that non-tic features of GTS may nonetheless be characteristic of GTS rather than other problems. For example, motor restlessness which is a symptom of sensorimotor activation accompanying GTS is also a symptom of ADHD. Clearly, an important step in clarifying diagnosis and the role of comorbidity is to develop a coherent account of the various manifestations of GTS, and in particular the precise form and function of tics.

\subsection{The consequence of collateral symptoms in GTS}

The impact of comorbidity in GTS touches on clinical manifestations and management. Cases with comorbidity are likely to show more severe symptoms, show poorer prognosis, and are more likely to be treatment-resistant (Leclerc, Forget, \& O'Connor, 2008). Children with GTS and comorbidity, in particular OCD and ADHD, show more behavioral problems and poorer psychosocial adaptation whether at school or in other domains. There is also the question of what problem to treat first, and whether treating one problem impacts on the treatment of other problems. For example, treatment strategies for treating hyperactivity involve medication, which can (at least temporarily) exacerbate tics. In addition, particularly in children, it is frequently comorbid behavioral problems (e.g., explosive outbursts) which are most disruptive for the family. The presence of other problems in GTS also adds to feelings of stress, inability to cope and low self-esteem. A further consequence is that existence of at least one comorbidity increase the probability of further comorbidity, such as OCD and hyperactivity, that substantially increases the risk of concurrent explosive outbursts (Budman et al., 2003). 
The clinician is frequently confronted with the issue of which problem to treat first. Usually there are multiple comorbidities and their assessment are often unreliable, in part because it is unclear which comorbidities are distinct from GTS or part of the same problem. For example, all the comorbidities in GTS have distinct tic-like features. Explosive outbursts may be viewed as emotional tics and what appear as OCD-like behaviors in GTS may in fact be complex tics, and hyperactivity may be a by-product of the heightened sensorimotor activation often found in GTS (O'Connor, 2002).

Tics are usually preceded by "premonitory urges," described by patients as growing tension of the ticcing muscle or as increased anxiety, which is temporarily relieved after performance of the tic (Leckman, Bloch, Scahill, \& King, 2006). These manifestations are very similar to OCD, in which subjects feel increased anxiety and discomfort until certain compulsions are performed (King \& Scahill, 2001). More precisely, the manifestation of OCD symptoms is characterized by recurrent intrusive thoughts (e.g. obsession) accompanied by repetitive, seemingly purposeful behaviors (e.g. compulsion), sufficiently severe to interfere with daily functioning. OCD appears in In half of GTS (Apter et al., 1992) in comparison with 3-4\% in the non-GTS adult population (Karno, Golding, Sorenson, \& Burnam, 1988; Zohar et al., 1992). Three main questions arise from these findings. How to discriminate OCD characteristics from typical symptoms of GTS? How to objectively characterize expression of motor tics in GTS and GTS+OCD? And finally, how to characterize these comorbid groups with neurocognitive measures. This will constitute one of the primary focuses of the current chapter.

\section{Neurobiological basis of Tourette}

\subsection{Can we identify specific cerebral structures underlying GTS symptoms?}

Studies using magnetic resonance imaging (MRI), have identified minor reduction in the putamen and the caudate nuclei when confounding variables such as sex, age, OCD, attention-deficit hyperactivity disorders (ADHD) and streptococcal infection were taken into account (Peterson et al., 2000). Other MRI and positron emission tomography (PET) studies consistently reported volumetric and metabolic reductions in lentiform (Braun et al., 1995; Eidelberg et al., 1997) and caudate nuclei (Bloch, Leckman, Zhu, \& Peterson, 2005; Hyde et al., 1995; Stoetter et al., 1992). The basal ganglia are not the sole cerebral structures involved in the pathogenesis of GTS. An extensive investigation (Peterson et al., 2007) comparing a large sample of GTS and controls aged between 6-63 years old, showed increased volumes of the head and medial surface of the hippocampus and the dorsal and ventral surfaces of the amygdala. Volumes of these subregions declined with age in the GTS group but not in controls, so the sub-regions were larger in GTS children, but significantly smaller in GTS adults than in the control group. In children and adults, volumes in these subregions correlated inversely with the severity of tic, suggesting that enlargement of these structures have a neuro-modulatory effect on tics. In addition to these networks, motor and sensorimotor cortices have showed metabolic increases associated with heightened activation in premotor cortex and supplementary motor area (SMA) with PET imaging (Braun et al., 1993; Eidelberg et al., 1997; Stoetter et al., 1992). Cortical thinning in sensorimotor areas was also correlated with tic severity and was most prominent in ventral portions of the homunculi that control the facial, orolingual and laryngeal muscles commonly involved in tic expressions (Sowell et al., 2008). In a recent review of 
neuroimaging studies, Sheppard et al., (1999) underlined that GTS patients may develop clinical levels of OCD and/or ADHD since all three disorders involve neuropathology of the Basal-Ganglia Thalamo Cortical (BGTC) pathways. For instance, GTS patients may have a dysfunction in sensorimotor and limbic BGTC circuits; OCD in the prefrontal and limbic BGTC pathways; and ADHD in the sensorimotor, orbitofrontal, and limbic BGTC circuits.

In summary, the most recent volumetric observations in structural brain imaging suggest that complex networks related to sensorimotor functions are involved in GTS rather than a defined region of interest. The next important question is to address the functional problem of how these altered cerebral networks affect cognitive processing in GTS.

\subsection{Neuropsychology of GTS}

A comprehensive understanding of this syndrome requires a multidimensional approach, ranging from clinical psychology and psychiatry to neurology and cognitive neuroscience. For instance, several studies have uncovered cognitive specificities in GTS such as deficit in learning for mathematics and written language (Brookshire, Butler, Ewing-Cobbs, \& Fletcher, 1994; Como, 2001), verbal fluency (Bornstein, 1991b; Brookshire et al., 1994) and nonverbal memory (Harris et al., 1995; Lavoie, Thibault, Stip, \& O'Connor, 2007; Schuerholz, Baumgardner, Singer, Reiss, \& Denckla, 1996). Other investigations proposed that GTS children achieved normal performances on tasks evaluating abstract concepts (Bornstein, 1990; Bornstein \& Baker, 1991; Braun et al., 1993; Harris et al., 1995; Schuerholz et al., 1996; Yeates, 1994), planning and response inhibition (Ozonoff \& Jensen, 1999) as well as verbal fluency (Braun et al., 1993; Mahone, Koth, Cutting, Singer, \& Denckla, 2001), whilst, on the other hand, others proposed several types of executive function impairments (Baron-Cohen, Cross, Crowson, \& Robertson, 1994; Bornstein, King, \& Carroll, 1983; Brookshire et al., 1994; Schuerholz et al., 1996; Sutherland, Kolb, Schoel, Whishaw, \& Davies, 1982). Additional investigations have reported abnormalities with motor skills tasks like the Purdue and Groove Pegboard (PGP) in children (Bornstein, 1990; Hagin, Beecher, Pagano, \& Kreeger, 1982), pre-adolescents (Bornstein, 1991a) and adults (O'Connor, Lavoie, Stip, Borgeat, \& Laverdure, 2008). Perhaps the most interesting observation is the finding that poorer performances on the PGP, during childhood, predicted worse adulthood tic severity and psychosocial functioning (Bloch, Sukhodolsky, Leckman, \& Schultz, 2006).

\subsection{Integration of neuropsychology and functional imaging}

Individuals with GTS do not necessarily have a characteristic neuropsychological profile which distinguishes them clearly from other psychiatric groups. The large array of behavioral problems in GTS touches various cognitive functions and the apparent lack of consistency in the neuropsychological results could be due to methodological problems considering that, in some cases; studies did not include a control group and often included small samples. Another possible confounding element could be related to the lack of sensitivity of the neuropsychological tests to tap subtle abnormalities often present in these groups. One solution is to adapt neuropsychological tasks to functional magnetic resonance imaging (fMRI) in order to record live brain activity during tic generation or cognitive and motor processing. In an elegant study using fMRI with GTS adults, Peterson et al. (1998) compared brain activity during blocks of time, during which tics were voluntarily 
suppressed or not suppressed. During tic suppression, prefrontal cortical, thalamic and basal ganglia areas were activated and less activation corresponded with higher tic severity which was consistent with volumetric studies.

In addition, there is often a problem in planning and execution of motor action in GTS. One of the first fMRI study investigating motor functions in GTS showed heightened activation in premotor cortex and SMA during a finger tapping task (Biswal et al., 1998). This, however, could depend on a non selective overactivity of the motor system or on a problem in modulating effort. To address that question, Serrien et al., (Serrien et al., 2002) showed that the SMA of the GTS patients have small or greatly reduced activation when executing a manipulative task as compared with a baseline condition. Nonetheless, cortical areas involved in movement preparation were continuously activated. It was hypothesized that the constant activation of SMA may explain the involuntary urges to move, preventing an accurate planning of voluntary behavior. These first fMRI results suggest that the problem may not be unidirectional with over- or under- activation of motor-related brain networks, but can also relate to a problem of modulation of effortfull and goal directed behavior. This also suggests a deficit not only in motor response inhibition but also in cognitive control. Recent brain imaging findings seems to point towards greater activation of bilateral frontostriatal regions in GTS, which accompanied poorer performance on the Stroop, a well known task of cognitive inhibition. This finding implied that greater activation of the frontostriatal system helps to maintain task performance in individuals with GTS (Marsh, Zhu, Wang, Skudlarski, \& Peterson, 2007). Another study (Baym, Corbett, Wright, \& Bunge, 2008) confirmed that GTS children exhibit increased activation in the direct pathway through the basal ganglia, as well as increased activation in the prefrontal cortex and the subthalamic nucleus during an inhibition control task. In that study, higher tic severity was associated with enhanced activation of dopaminergic nuclei, cortical, striatal and thalamic regions (i.e. direct pathway) and with greater engagement of the subthalamic nucleus area, suggestive of a compensatory mechanism.

In summary, findings from both neuropsychology and neuroimaging suggest the presence of a dysfunction in a cortico-striatal-thalamo-cortical (CSTC) circuit loop. More precisely, recent findings pinpoint a chronic overactivation in cerebral regions associated with motor processing. Finally it seems that a problem of cognitive inhibition is present, which is likely to interfere with accurate planning and execution of voluntary movements. The next challenge is to seek integration of these functional neuroimaging results with real-time information processing in GTS.

\subsection{Cognitive electrophysiology and experimental neuropsychology in GTS}

As demonstrated in the previous section, despite recent developments in the understanding of GTS, most hypotheses consider the behavioral, cognitive and neurobiological levels independently, whereas an integrative model of GTS, that combines all levels of functioning, would address the relationship between these levels. Tools for such multi-level research would require sensitivity to high-speed cognitive processing, which changes in a matter of milliseconds in synchrony with a specific time-lock event. One solution is the Event-Related Potentials (ERP) which are cortical electrical deflections derived from the time-locked averaged EEG signal and labeled by their polarity and temporal ranges in milliseconds (i.e. 
P300) (Sarason, Johnson, \& Siegel, 1978). An initial study, using an auditory oddball ${ }^{1}$ paradigm, with GTS patients, has shown an abnormal N100/P200 complex, while finding an intact P300 (Van de Wetering, Martens, Fortgens, Slaets, \& van Woerkom, 1985) so, suggesting a deficit in attention and vigilance, but with intact memory updating processes. Other studies found larger N100 amplitude to both target and non-target stimuli, proposing that GTS patients allocate more attention than controls in processing both relevant and non relevant stimuli (van Woerkom, Roos, \& van Dijk, 1994). However, recent findings with an auditory-visual oddball (Johannes, Wieringa, Nager et al., 2001), found a reduced amplitude of the P300 indicating an increased interference of visual task demands with auditory target perception, which suggested a deficit in cognitive control in GTS patients.

Despite these interesting results, it has been unclear whether this particular problem is associated with a cognitive control deficit and/or with a core motor deficit interfering with cognitive control. An alternative hypothesis is that these results are not only the reflection of a deficit per se, but represent instead a mechanism that acts to overcome a motor inhibition problem. For instance, the readiness potential (RP) activation was consistently larger over frontal and smaller over central areas in the GTS group (see Rothenberger et al., 1982; 1986) supporting a possible frontal compensation hypothesis. However, the extent to which the motor preparation is linked with actual cerebral activity has not been systematically analyzed. In one of our earlier studies, we showed that patients with chronic tic disorder failed to show any relationship between reaction times and cortical activation (i.e. RP) during a fore period reaction time task (O'Connor, Lavoie, Robert, Stip, \& Borgeat, 2005). This finding supports the possibility that people with tic disorders may not be able to modulate cortical activation optimally when planning and executing motor responses.

The caveat with the RP, nonetheless, resides in its high variability, probably reflecting overlapping of non motor as well as motor activity. Also, its early onset may implicate general anticipatory processes rather than the specific cortical preparation preceding movement (Trevena \& Miller, 2002). To circumvent this problem, the Lateralized Readiness Potential (LRP), which has its generators in the primary motor cortex (Requin \& Riehle, 1995), the SMA (Rektor, 2002) and the basal ganglia (Rektor et al., 2003) represents an excellent candidate measure of motor processing, that could be affected in GTS. Specifically, the LRP has been shown to be a marker of selective motor activation, representing the differential engagement of the left and right motor cortices in the preparation and initiation of motor responses (Coles, 1989; Kutas \& Donchin, 1980). The LRP could be analyzed timelocked to the stimulus or to the response, reflecting two levels of processing (at premotor or at the motor level). Using LRPs, the team of Johannes et coll. (Johannes, Wieringa et al., 2001b) failed to show any response-specific difference to GTS patients. In this paradigm, however, stimulus-locked LRPs were pooled across conditions and the peak amplitude was analyzed as a non-specific measure of motor processing, which may have reduced its sensitivity to detect any subtle motor processing differences. To resolve this limitation, we investigated LRPs in GTS adults across diverse conditions of stimulus-response interference (Thibault, O'Connor, Stip, \& Lavoie, 2008). GTS groups showed faster response times and

\footnotetext{
${ }^{1}$ During the oddball task, a train of rare stimuli is presented among frequent ones. The task is to identify rare-targets among frequents. This normally triggers the P300 component, which shows larger amplitude to the rare than to the frequent stimuli.
} 
earlier LRP onset to the incompatible condition, which was correlated with tic severity. These findings support the hypothesis of faster motor program retrieval, congruent with the hypothesis of a neuro-modulatory mechanism. This allow a compensation mechanism to achieve normal or above normal motor performance (Biswal et al., 1998; Eidelberg et al., 1997). Interestingly, these results are consistent with observations that, for instance, activities that require focused attention and fine motor dexterity, such as playing a musical instrument are frequently associated with the momentary disappearance of tics (Swain et al., 2007).

In sum, previous ERP studies showed, first, that people with GTS may not be able to modulate cortical activation optimally, when planning and executing motor responses, and secondly, they need to compensate to achieve normal of better performances. However, some results are contradictory and could be related to the presence of other symptomatic elements or to an erroneous diagnosis. To understand the specificity of other findings, we propose to propose to take into account more thoroughly the presence of other conditions often associated with problems of inhibition.

\subsection{The puzzling problem of inhibition in GTS and OCD}

Even if earlier findings are consistent with an inhibitory dysfunction hypothesis in GTS, there are a lot of inconsistencies in the literature and many studies find no evidence of such deficit in children (Channon, Pratt, \& Robertson, 2003; Ozonoff \& Jensen, 1999) and adults (Channon, Flynn, \& Robertson, 1992; Channon et al., 2003; Ray Li, Hsu, Wang, \& Ko, 2006). What could be the reason of these inconsistencies? To address that point, Ozonoff and collaborators (Ozonoff, Strayer, McMahon, \& Filloux, 1998) suggested that inhibitory deficits could be largely caused by the presence of comorbid disorders that often arise in GTS. Indeed, the authors found no performance difference between relatively pure GTS (without comorbidity) and control children, in a negative priming task. In fact, only the GTS+ADHD and/or the OCD showed signs of an inhibitory dysfunction compared to controls and GTS without comorbidity. Again, the comorbidity factor appears very important in altering the neurocognitive profile of GTS. In general, frequent comorbidities between GTS and OCD, along with behavioral similarities between them, leads several researchers to propose that they might share common neurophysiological bases (Pauls, 1992; Pauls, Alsobrook, Goodman, Rasmussen, \& Leckman, 1995; Pauls, Towbin, Leckman, Zahner, \& Cohen, 1986; Sheppard et al., 1999).

\subsection{Inhibitory function and attention in dissociating GTS and OCD}

However, there are several points that discriminate GTS and OCD. Brain imaging investigations suggest that both GTS and OCD could be initially provoked by a default in inhibitory functions, caused by a metabolic reduction in basal ganglia structures projecting to either the prefrontal and primary motor cortices in GTS, or the orbitofrontal cortex and the anterior cingulate cortex in OCD (Menzies et al., 2008; Mink, 2001; Saxena, Brody, Schwartz, \& Baxter, 1998; Sheppard et al., 1999). The prefrontal cortex plays an important role in the ability to orchestrate thought and action in accordance with internal goals and the means to achieve them (Miller \& Cohen, 2001), while the primary motor cortex is responsible for simple static or repetitive movements as well as complex preprogrammed or spontaneous purposeful movements (Lassen \& Ingvar, 1990). The orbitofrontal cortex 
appears to be fundamentally critical for outcome-guided behavior and also for facilitating changes in behavior in the face of unexpected outcomes (e.g. habit reversal) (Murray, O'Doherty, \& Schoenbaum, 2007). In OCD, alteration of this circuit could be responsible for functional deficit in procedural memory as assessed by the pursuit rotor test (Roth, Baribeau, Milovan, O'Connor, \& Todorov, 2004), while another study found that these functions were well preserved in GTS (Marsh, Alexander, Packard, Zhu, \& Peterson, 2005). Common problems associated with both OCD as well as GTS may stem from their difficulty to inhibit interference from non-relevant cues. For instance, a semantic inhibition task revealed that GTS and OCD groups were consistently disadvantaged in the more demanding inhibition conditions compared to matched controls (Rankins, Bradshaw, \& Georgiou-Karistianis, 2006). This difficulty to inhibit interference could also rely on a problem of overfocused attention particularly salient in OCD (Savage et al., 1994). This hypothesis was confirmed in ERP research, where attention-related components peaked at a faster latency in OCD (Towey et al., 1990; Towey et al., 1993; Towey et al., 1994) than in a control group, which was not found with GTS (Johannes, Wieringa, Nager et al., 2001; Johannes et al., 2002; van Woerkom, Fortgens, Rompel-Martens, \& Van de Wetering, 1988).

\subsection{Inhibitory and sensorimotor integration specificity in GTS}

Even if these findings underline differences and similarities in GTS and OCD, only few ERP investigations have compared pure GTS, comorbid GTS+OCD and pure OCD in the same experiment. One of our recent study (Thibault et al., 2008) focusing on comorbidity in GTS, showed a normal P200, whilst the P300 amplitude was clearly affected by the occurrence of clinical symptoms. The OCD and the GTS+OCD group showed reduced rare-target P300 amplitude, mainly in the right anterior region, but otherwise did not differ significantly from each other. The target P300 amplitude was also negatively correlated with OCD, which confirmed numerous findings reported in OCD (Beech, Ciesielski, \& Gordon, 1983; Malloy, Rasmussen, Braden, \& Haier, 1989; Miyata et al., 1998; Morault, Guillem, Bourgeois, \& Paty, 1998; Morault, Bourgeois, Laville, Bensch, \& Paty, 1997; Oades, Dittmann-Balcar, Schepker, Eggers, \& Zerbin, 1996; Sanz, Molina, Martin-Loeches, Calcedo, \& Rubia, 2001; Thibault et al., 2008; Towey et al., 1994). Conversely, participants suffering from GTS showed larger target P300 amplitude, positively correlated with tic frequency. These results suggest that OCD and GTS symptoms have opposing influences on the P300 amplitude during a nonmotor oddball task. During a motor inhibition task, however, the profile was different. Inhibitory mechanisms were investigated in a go-nogo task to assess whether sensorimotor integration processes are similar in GTS and OCD (Johannes, Wieringa et al., 2001a). Results showed that the 'no-go' were associated with a frontal shift of the so-called $\mathrm{NGA}^{2}$ in the GTS, but not in the OCD group. With a comparable STOP-task, we also found results similar to Johannes et al., (Johannes, Wieringa et al., 2001a) where the NGA related to the stop/inhibition was larger over frontal areas in the GTS group even in the absence of OCD comorbidity (Thibault et al., 2009). This finding led to the hypothesis that an overactivated frontal inhibitory function is specific to GTS patients.

\footnotetext{
2 The No-Go anteriorization (NGA) is a frontally distributed ERP more prominent in response to response inhibition at approximately $400 \mathrm{~ms}$ post-stimulus. It represents a subtraction (e.g. voltage subtraction between go and no-go ERPs).
} 


\subsection{GTS children growing up: A model of inhibition and developmental neuroplasticity}

GTS is characterized by its fluctuating nature over time, and its developmental trajectory needs to be considered. Through longitudinal studies, certain hypotheses have underlined cerebral anomalies associated with symptoms persistency in adulthood. Peterson and collaborators (Peterson et al.2001) proposed that because it is present in every age group, the hypometabolism of the caudate nucleus could constitute a feature of GTS. Moreover, the volume decrease of the putamen, the internal globus pallidus and prefrontal areas, as well as the increase of volume of premotor areas, are uniquely present among adults, which suggests that they are associated with specific pathological mechanisms contributing to the maintenance or inhibition of symptoms among sub-groups of adult with significant symptoms of GTS persisting during adulthood. Among these individuals, there seems to be a failure of cerebral plasticity mechanisms that allows compensating the presence of tics by an overactivation of a motor inhibition process. Unlike adults, children with GTS have a larger orbitofrontal volume (Peterson 2001; Peterson et al.2001; Spessot, Plessen, \& Peterson, 2004), which would constitute an adaptive plasticity in response to the expression of tics which, in turn, would help to inhibit them more easily. With the maturation of the prefrontal cortex during adolescence, this mechanism could gain strength and explain the symptom decrease during adolescence and early adulthood. Among adults with persisting symptoms, this prefrontal compensation could not occur. The decrease in volume of the putamen and globus pallidus, and thus the increase in volume of the premotor area, would only be secondary to this compensation.

These neurodevelopmental observations are compatible with current cognitive-behavioral models (O'Connor, 2002; O'Connor, 2005; O'Connor et al., 2009). If the evolution and fluctuation of symptoms is related to a form of cerebral plasticity, then we propose that cognitive-behavioral treatment (CBT) will, in turn, improve symptoms as well as favoring neurophysiological changes corresponding to a normalization of cerebral function, a phenomenon which has recently been observed by our team (Branet, Hosatte-Ducassy, O'Connor, \& Lavoie, 2010; Lavoie, Imbriglio, Stip \& O'Connor, 2011; O'Connor 2005; O'Connor et al. 2001; O'Connor et al. 2008).

\section{Treatment approaches with Gilles de la Tourette Syndrome}

\subsection{Pharmacological treatments}

Pharmacological treatments remain the intervention of choice to help people with GTS. Various treatments have been proposed to help patients, but the majority of prescription drugs as much among adults as among children with GTS, show a variable response, even sometimes on the same individual. From the beginning, let us mention that no drug can lead to the complete remission of this syndrome and the dosage is usually graduated according to the presence of the dominant tic or behavioral symptoms. Because of the dominant hypothesis of tics as a problem of the motor CSTC circuit and the dopaminergic system, dopamine antagonist neuroleptics are routinely the main treatment. Therefore, many researchers have observed that pharmacological agents that trigger an increase (agonist) in dopaminergic functions will exacerbate tics (Golden, 1974; Price, Leckman, Pauls, Cohen, \& Kidd, 1986; Riddle, Hardin, Towbin, Leckman, \& Cohen, 1987), whereas those that bring a decrease (antagonist) of the dopaminergic action tend to reduce the tic frequency (Shapiro et al., 1989; Lombroso et al., 1995). 
Haloperidol (neuroleptic) and clonidine (antihypertensive) are currently the favored medication for the management of tics (Bruun \& Budman, 1996; Dion, Annable, Sandor, \& Chouinard, 2002; Gilbert et al., 2004; Scahill, Leckman, Schultz, Katsovich, \& Peterson, 2003). Among children and teenagers, controlled trials have shown that the frequency of tics decreases by $50 \%$ after the use of haloperidol or pimozide (Sallee, Nesbitt, Jackson, Sine, \& Sethuraman, 1997). However, typical antipsychotics like Haldol may cause extrapyramidal signs, characterized by involuntary movements, impatience and a need to constantly move and significant trembling among other symptoms. Atypical drug therapy or drug combinations are reserved for more complex cases as well as in the presence of associated disorders. However, side effects also occur in approximately $80 \%$ of individuals, and only $20-$ $30 \%$ of patients afflicted with GTS continue pharmacological treatment for an extended period (Peterson, Campise, \& Azrin, 1994). The effectiveness of risperidone (atypical neuroleptic) has progressively been proven to reduce tics, despite the possibility of significant long term side effects, such as an increased risk of hyperglycemia and diabetes (see review of Lavenstein, 2003). Other pharmacological agents (antidepressants or other neuroleptics) can provide positive results in reducing tics, but these results are often inconsistent and generally come from unique cases, non randomized trials (Pringsheim \& Marras, 2009).

In addition, the consumption of psychostimulants (e.g. methylphenidate) was not recommended given the increase in tics in children with concomitant ADHD (Bremness \& Sverd, 1979; Golden, 1974; Golden, 1977). However, the majority of recent studies showed that psychostimulants decrease ADHD symptoms without involving much of an increase in the long-term tics (for a review see Erenberg, 2006). Furthermore, other studies have shown that the tic increase due to psychostimulants, is no longer visible after approximately 18 weeks of treatment, so challenging the restriction on the use of psychostimulants among children with GTS and ADHD (Debes, Hjalgrim, \& Skov, 2009). However, it is the caregiver's responsibility to inform the family of the possible secondary effects of psychostimulants.

\subsection{Cognitive-behavioral treatment}

Alternative treatments have shown some success with tic management, including hypnotism, relaxation, muscle feedback, awareness training, negative reinforcement, response prevention and massed practice (Bergin et al., 1998; Azrin et Peterson, 1988; 1990). Therapeutic interventions target not only tic symptoms, but also coping strategies that can modify the unique impact that GTS symptoms may have on an individual's well being (Petersen and Cohen, 1998). The most compelling treatment medium for managing the tics themselves seems to be behavioral treatment, in particular 'habit reversal' (HR) (Azrin and Peterson, 1988). This package involves multiple stages, including relaxation, awareness, contingency training and positive reinforcement of not ticcing and the crucial element of practice of a competitive antagonistic response. This latter technique involves tensing the muscle antithetical and incompatible with the tic-implicated muscle. Awareness training and competing response training seem the most crucial elements of the program (Miltenberger et al., 1988), which can be applied to both tics and habit disorders. Three developmentally normal adolescents with chronic hair pulling were treated with a simplified HR procedure and resulted in an immediate reduction to near-zero levels of hair 
pulling, with one to three booster sessions required to maintain these levels (Rapp et al., 1998). Azrin \& Peterson (1988) report an improvement of between $64-100 \%$ in several studies using this method in populations with both simple tics and/or GTS. Peterson \& Azrin, (1992) compared the efficacy of awareness, relaxation, and HR in six participants using a within participants design. HR produced the largest overall reduction in tics (55\%) and led to the largest reduction in total tics (95\%) for any individual, but there was no significant difference between treatments. In an initial wait-list controlled treatment trial, a cognitive-behavioral package based on HR showed significant post treatment clinical improvement for $52 \%$ of the adult patients (O'Connor et al. 2001).

However, these results were collected during experiments with small numbers of participants from various populations affected with chronic tics, GTS or habit disorders. Recently this type of behavioral therapy was evaluated in a multi-site randomized controlled trial which followed 126 children between 9 to 17 years-old afflicted with GTS or chronic tic (Piacentini et al., 2010). In this study, all children were randomly assigned to 8 sessions of behavioral therapy during 10 weeks or to equivalent support and education therapy sessions. The sessions of behavioral treatment helped to significantly decrease the tic symptoms in comparison with the support therapy (in 53\% vs. 19\% of cases respectively) with, in addition, the effects lasting 6 months in $87 \%$ of cases.

\subsection{Multilevel treatment of GTS: Integrating cognitive, behavioral and neurophysiological findings}

Over the last 10 years, our group has conducted a number of studies exploring the cognitive behavioral and psychophysiological manifestations of motor activation in GTS/Chronic Tic, with the aim of linking the multi-level processes evoking tic onset with behavioral management procedures (Lavoie et al., 2008; Leclerc et al., 2008; O'Connor, 2005; O'Connor, 2005; O'Connor et al., 2009; O'Connor et al., 2005; O'Connor et al., 2008; Thibault et al., 2009). As part of the research program, we developed a style of planning questionnaire (STOP) which measures style of planning in everyday life. The STOP has now been validated and has good reliability and discriminates between tic disorder and controls, (O'Connor, 2005). Its three main factors are: overactivity, overpreparation and overrigidity in planning action. The results suggest that all GTS show elevated scores on the first two factors. In addition, the overactivity subscale correlates highly with the Tourette symptom global subscale of motor restlessness.

These experimental and clinical findings have led to elaboration of a cognitive behavioral/psychophysiological model of treatment (O'Connor, 2005) which proposes: 1) an over-active style of planning that prevents optimal preparation for action; 2) this style leads to problems regulating arousal/inhibition processes particularly under circumstances where regulation is open-looped, controlled, and has unpredictable parameters; 3 ) such high levels of motor activation create tension and frustration and are likely to evoke ticcing; 4 ) hence a CBT package which addresses the cognitive psychophysiological sources of motor activation who will reduce background tension and prevent tic onset. Whereas traditional HR targets solely the tic implicated muscle in a competing response, an important additional component in our CBT program is modification of excessive overall motor activation, by 
targeting cognitive and behavioural/physiological sources creating tension. An initial study using this CBT program demonstrated its efficacy on 47 chronic tic and 43 habit disorder (other manual impulse disorder, e.g., hair pulling, nail biting, teeth grinding) receiving a 4month treatment program. Thirty-eight (22 chronic tic TD, 16 habit disorders) were placed on a wait-list control group, which subsequently received treatment. The treatment approach combined awareness training, relaxation (including modification of a tensionproducing overactive style of action), and habit-reversal training, with more general cognitive restructuring of anticipations linked to ticcing. Sixty-five percent of completers reported between 75 and 100\% control over the tic. At 2-year follow-up, 52\% rated $75-100 \%$ control. There were also significant changes post-treatment in measures of self-esteem, anxiety, depression and style of planning action (O'Connor et al., 2001). The majority of participants in this study were diagnosed with light to moderate symptoms.

\subsection{Cognitive-behavioral treatment and his impact on brain plasticity}

A strong relationship has also been found between symptom reduction following a CBT and brain glucose metabolism in patients with OCD. Using PET imaging, Baxter et al., (Baxter, 1990) found a decrease in the glucose metabolic rate in the right head of the caudate nucleus when OCD was treated successfully with fluoxetine or CBT. A further investigation (Brody et al., 1998) suggested that subjects with differing patterns of metabolism preferentially respond to CBT versus medication. Left orbital-frontal cortex metabolism alone was selected as predicting treatment response in the CBT treated group.

Our team also found interesting impact of CBT on motor dexterity (O'Connor et al., 2008) as well as comparable effect of CBT on those receiving or not medication (O'Connor et al., 2009). One recent research also showed not only behavioral, but also electro-cortical effects post CBT. Thus, before treatment, GTS patients showed reduced electrophysiological response in comparison with the control group during a motor inhibition task. Following CBT administration, this response was normalized concomitantly with decrease of tics frequency (Lavoie et al., 2011). Despite the innovation and evolutionary character of this model, more studies are nonetheless necessary in order to validate the foundation and the efficiency of this intervention program to better assist clinicians in an innovative way.

In sum, CBT and pharmacotherapy focusing on motor regulation can lead to significant clinical improvement in GTS. Brain imaging results after CBT and/or pharmacotherapy in patients with OCD also suggest strong relationships between altered brain activity and symptoms reduction.

\section{Conclusion}

GTS is a complex neuropsychiatric disorder that affects more people than previously thought. In the last decade, past research has made progress in the treatment of this syndrome, but many questions remain open. Why many patients failed to respond to current treatment? Why are they often misdiagnosed? Are the symptoms really disappearing in adults? These questions can only be approached with a multidisciplinary team combining neurologist, psychologist and neuroscientist from different background. So, a unidisciplinary approach disallows integrating the cognitive, structural and the functional 
levels of cerebral functioning. Structured interviews are valuable to follow up on clinical states, but they only yield superficial or indirect information on brain functioning. A coherent model of GTS from a single approach is unlikely, since this pathology is multifaceted. A cognitive-behavioral approach links impairments with the clinical expression of the illness that will impact on therapeutic strategies. However, it provides little information about the cerebral roots of the disease. Neuropsychology allows valid inferences about discrete anomalies, but inferences are mainly based on our knowledge of focal lesions, not on functional disorders. Brain imaging is appropriate for identifying localized metabolic abnormalities. However, it is limited by its low temporal resolution that does not take account of the real-time dynamics of the neurocognitive mechanisms involved in the cascade of information processing (Logothetis, 2008). ERPs provide clues to the cerebral activation underlying cognitive processes. But the activity recorded over the scalp might also reflect deeper subcortical activity, which can be only extrapolated or modeled through the analysis of multiple generating sources at best. Moreover, the scalp distribution has often been neglected in clinical studies, so losing both spatial and temporal resolution. However, the ERP approach might still be insufficient because the main limitation will always reside in its low spatial resolution even with a larger electrode array. An alternative will be the use of fMRI cluster techniques to seed dipoles into the EEG head model. Another important point is to anchor both measures to behavioral and neurocognitive expressions of GTS and OCD. As a result, other associated symptoms are often underestimated in populations of GTS, leading to incorrect diagnostic or treatment. To address that issue, we propose in depth neuropsychological evaluation as well as brain activity recordings in order to characterize a particular profile pertaining to GTS and/or OCD groups. The potential benefit of the current approach will be to extract a complete profile allowing prediction of symptom development or treatment success.

From a clinical perspective, effective and individualized therapeutic action should not only include the modification of motor symptoms and inhibition, but should also include cognitive strategies to deal with tics. It is necessary to broaden our conception of GTS in order to see it not only as a neurological, but also as a psychobiological syndrome, because a multifactorial treatment induces a maximal effect on many levels and helps to decrease and to better manage the frequency and intensity of the symptoms. This approach needs to combine nonetheless both cognitive and behavioral perspective, while taking into account physiological aspects that can also exacerbate the behavioral reaction.

In conclusion, two considerations seem fundamental for the development of specialized interventions for GTS in the near future. First, integrating psychophysiological technology as an instrument of treatment: these new possibilities can support cognitive and behavioral management through learning self-controlled strategies. Second, the dissemination of study results on alternate interventions or other front lines must be done. Finally, treatments for GTS symptoms, empirically acknowledged to be effective, should be known by the public and be more accessible.

\section{Acknowledgments}

This work was supported in part by a Canadian Institutes of Health Research (CIHR) operating grant (MOP57936), a Fonds pour la Recherche en Santé du Québec (FRSQ), team research grant (Subvention à la recherche en santé mentale -FRSQ \# 20573). 


\section{References}

Abelson, J. F., Kwan, K. Y., O'Roak, B. J., Baek, D. Y., Stillman, A. A., Morgan, T. M., et al. (2005). Sequence variants in SLITRK1 are associated with Tourette's syndrome. Science, 310(5746), 317-320.

Alsobrook, J. P., 2nd, \& Pauls, D. L. (2002). A factor analysis of tic symptoms in Gilles de la Tourette's syndrome. Am J Psychiatry, 159(2), 291-296.

APA. (2000). Diagnostic and Statistical Manual of Mental Disorders (4th edition-Text revision ed.). Washington DC: American Psychiatric Association.

Apter, A., Pauls, D. L., Bleich, A., Zohar, A. H., Kron, S., Ratzoni, G., et al. (1992). A population-based epidemiological study of Tourette syndrome among adolescents in Israel. Adv Neurol, 58, 61-65.

Baron-Cohen, S., Cross, P., Crowson, M., \& Robertson, M. (1994). Can children with Gilles de la Tourette syndrome edit their intentions? Psychol.Med., 24(1), 29-40.

Baxter, L. R. (1990). Brain imaging as a tool in establishing a theory of brain pathology in obsessive compulsive disorder. J Clin Psychiatry, 51 Suppl, 22-25; discussion 26.

Baym, C. L., Corbett, B. A., Wright, S. B., \& Bunge, S. A. (2008). Neural correlates of tic severity and cognitive control in children with Tourette syndrome. Brain, 131(Pt 1), 165-179.

Beech, H. R., Ciesielski, K. T., \& Gordon, P. K. (1983). Further observations of evoked potentials in obsessional patients. Br J Psychiatry, 142, 605-609.

Biswal, B., Ulmer, J. L., Krippendorf, R. L., Harsch, H. H., Daniels, D. L., Hyde, J. S., et al. (1998). Abnormal cerebral activation associated with a motor task in Tourette syndrome. American Journal of Neuroradiology, 19(8), 1509-1512.

Bloch, M. H., Leckman, J. F., Zhu, H., \& Peterson, B. S. (2005). Caudate volumes in childhood predict symptom severity in adults with Tourette syndrome. Neurology, 65(8), 12531258.

Bloch, M. H., Sukhodolsky, D. G., Leckman, J. F., \& Schultz, R. T. (2006). Fine-motor skill deficits in childhood predict adulthood tic severity and global psychosocial functioning in Tourette's syndrome. J Child Psychol Psychiatry, 47(6), 551-559.

Bornstein, R. A. (1990). Neuropsychological performance in children with Tourette's syndrome. Psychiatry Research, 33(1), 73-81.

Bornstein, R. A. (1991a). Neuropsychological correlates of obsessive characteristics in Tourette syndrome. J.Neuropsychiatry Clin.Neurosci., 3(2), 157-162.

Bornstein, R. A. (1991b). Neuropsychological performance in adults with Tourette's syndrome. Psychiatry Res, 37(3), 229-236.

Bornstein, R. A., \& Baker, G. B. (1991). Neuropsychological performance and urinary phenylethylamine in Tourette's syndrome. J Neuropsychiatry Clin Neurosci, 3(4), 417421.

Bornstein, R. A., King, G., \& Carroll, A. (1983). Neuropsychological abnormalities in Gilles de la Tourette's syndrome. J.Nerv.Ment.Dis., 171(8), 497-502.

Branet, I., Hosatte-Ducassy, C., O'Connor, K. P., \& Lavoie, M. E. (2010). Motor processing and brain activity are related to cognitive-behavioral improvement in chronic tic and habit disorders. International Journal of Psychophysiology., 77(3).

Braun, A. R., Randolph, C., Stoetter, B., Mohr, E., Cox, C., Vladar, K., et al. (1995). The functional neuroanatomy of Tourette's syndrome: an FDG-PET Study. II: Relationships between regional cerebral metabolism and associated behavioral and cognitive features of the illness. Neuropsychopharmacology, 13(2), 151-168. 
Braun, A. R., Stoetter, B., Randolph, C., Hsiao, J. K., Vladar, K., Gernert, J., et al. (1993). The functional neuroanatomy of Tourette's syndrome: an FDG-PET study. I. Regional changes in cerebral glucose metabolism differentiating patients and controls. Neuropsychopharmacology, 9(4), 277-291.

Bremness, A. B., \& Sverd, J. (1979). Methylphenidate-induced Tourette syndrome: case report. American Journal of Psychiatry, 136, 1334-1335.

Brody, A. L., Saxena, S., Schwartz, J. M., Stoessel, P. W., Maidment, K., Phelps, M. E., et al. (1998). FDG-PET predictors of response to behavioral therapy and pharmacotherapy in obsessive compulsive disorder. Psychiatry Res, 84(1), 1-6.

Brookshire, B. L., Butler, I. J., Ewing-Cobbs, L., \& Fletcher, J. M. (1994). Neuropsychological characteristics of children with Tourette syndrome : Evidence for a nonverbal learning disability?, Journal of Clinical and Experimental Neuropsychology (Vol. 16, pp. 289-302).

Bruun, R. D., \& Budman, C. L. (1996). Risperidone as a treatment for Tourette's syndrome. Journal of clinical psychiatry., 57(1), 29-31.

Budman, C. L., Bruun, R. D., Park, K. S., Lesser, M., \& Olson, M. (2000). Explosive outbursts in children with Tourette's disorder. J Am Acad Child Adolesc Psychiatry, 39(10), 1270-1276.

Budman, C. L., Bruun, R. D., Park, K. S., \& Olson, M. E. (1998). Rage attacks in children and adolescents with Tourette's disorder: a pilot study. J Clin Psychiatry, 59(11), 576-580.

Budman, C. L., Rockmore, L., Stokes, J., \& Sossin, M. (2003). Clinical phenomenology of episodic rage in children with Tourette syndrome. J Psychosom Res, 55(1), 59-65.

Burd, L., Kerbeshian, P. J., Barth, A., Klug, M. G., Avery, P. K., \& Benz, B. (2001). Long-term follow-up of an epidemiologically defined cohort of patients with Tourette syndrome. J Child Neurol, 16(6), 431-437.

Carter, A. S., O'Donnell, D. A., Schultz, R. T., Scahill, L., Leckman, J. F., \& Pauls, D. L. (2000). Social and emotional adjustment in children affected with Gilles de la Tourette's syndrome: associations with ADHD and family functioning. Attention Deficit Hyperactivity Disorder. J Child Psychol Psychiatry, 41(2), 215-223.

Channon, S., Flynn, D., \& Robertson, M. M. (1992). Attentional deficits in Gilles de la Tourette syndrome, Neuropsychiatry, Neuropsychology and Behavioral Neurology (Vol. 5, pp. 170-177).

Channon, S., Pratt, P., \& Robertson, M. M. (2003). Executive function, memory, and learning in Tourette's syndrome. Neuropsychology, 17(2), 247-254.

Coles, M. G. (1989). Modern mind-brain reading: psychophysiology, physiology, and cognition. Psychophysiology, 26(3), 251-269.

Como, P. G. (2001). Neuropsychological function in Tourette syndrome (pp. 103-111).

Debes, N., Hjalgrim, H., \& Skov, L. (2009). The Presence of Attention-Deficit Hyperactivity Disorder (ADHD) and Obsessive-Compulsive Disorder Worsen Psychosocial and Educational Problems in Tourette Syndrome. J Child Neurol.

Dion, Y., Annable, L., Sandor, P., \& Chouinard, G. (2002). Risperidone in the treatment of tourette syndrome: a double-blind, placebo-controlled trial. J Clin Psychopharmacol, 22(1), 31-39.

Eidelberg, D., Moeller, J. R., Antonini, A., Kazumata, K., Dhawan, V., Budman, C., et al. (1997). The metabolic anatomy of Tourette's syndrome. Neurology, 48(4), 927-934. 
Erenberg, G. (2006). The Relationship Between Tourette Syndrome, Attention Deficit Hyperactivity Disorder, and Stimulant Medication: A Critical Review. Seminars in Pediatric Neurology 12, 217-221.

Findley, D. B., Leckman, J. F., Katsovich, L., Lin, H., Zhang, H., Grantz, H., et al. (2003). Development of the Yale Children's Global Stress Index (YCGSI) and its application in children and adolescents ith Tourette's syndrome and obsessive-compulsive disorder. J Am Acad Child Adolesc Psychiatry, 42(4), 450-457.

Freeman, R. D. (2007). Tic disorders and ADHD: answers from a world-wide clinical dataset on Tourette syndrome. Eur Child Adolesc Psychiatry, 16 Suppl 1, 15-23.

Freeman, R. D., Fast, D. K., Burd, L., Kerbeshian, J., Robertson, M. M., \& Sandor, P. (2000). An international perspective on Tourette syndrome: selected findings from 3,500 individuals in 22 countries. Dev Med Child Neurol, 42(7), 436-447.

Gaze, C., Kepley, H. O., \& Walkup, J. T. (2006). Co-occurring psychiatric disorders in children and adolescents with Tourette syndrome. J Child Neurol, 21(8), 657-664.

Gilbert, D. L., Bansal, A. S., Sethuraman, G., Sallee, F. R., Zhang, J., Lipps, T., et al. (2004). Association of cortical disinhibition with tic, ADHD, and OCD severity in Tourette syndrome. Movement disorders 19(4), 416-425.

Gilles de la Tourette, G. (1885). Étude sur une affection nerveuse caractérisée par de l'incoordination motrice accompagnée d'écholalie et de coprolalie. Archives de Neurologie, 9, 19-42; 158-200.

Golden, G. S. (1974). Gilles de la Tourette's syndrome following methylphenidate administration. Developmental Medicine and Child Neurology 16:, 76-78.

Golden, G. S. (1977). The effect of central nervous system stimulants on Tourette syndrome. Ann.Neurol., 2(1), 69-70.

Hagin, R. A., Beecher, R., Pagano, G., \& Kreeger, H. (1982). Effects of Tourette syndrome on learning. Advances in neurology, 35, 323-328.

Harris, E. L., Schuerholz, L. J., Singer, H. S., Reader, M. J., Brown, J. E., Cox, C., et al. (1995). Executive function in children with Tourette syndrome and/or attention deficit hyperactivity disorder. J.Int.Neuropsychol.Soc., 1(6), 511-516.

Hyde, T. M., Stacey, M. E., Coppola, R., Handel, S. F., Rickler, K. C., \& Weinberger, D. R. (1995). Cerebral morphometric abnormalities in Tourette's syndrome: a quantitative MRI study of monozygotic twins. Neurology, 45(6), 1176-1182.

Itard, J. (1825). Mémoire sur quelques fonctions involontaires des appareils de la locomotion, de la préhension et de la voix. Archives Générales de Médecine, 8, 385-407.

Johannes, S., Wieringa, B. M., Mantey, M., Nager, W., Rada, D., Muller-Vahl, K. R., et al. (2001a). Altered inhibition of motor responses in Tourette syndrome and Obsessive-Compulsive disorder. Acta Neurologica Scandinavica, 104, 36-43.

Johannes, S., Wieringa, B. M., Mantey, M., Nager, W., Rada, D., Muller-Vahl, K. R., et al. (2001b). Altered inhibition of motor responses in Tourette Syndrome and Obsessive-Compulsive Disorder. Acta Neurol Scand, 104(1), 36-43.

Johannes, S., Wieringa, B. M., Nager, W., Muller-Vahl, K. R., Dengler, R., \& Munte, T. F. (2001). Electrophysiological measures and dual-task performance in Tourette syndrome indicate deficient divided attention mechanisms. European journal of neurology 8(3), 253-260.

Johannes, S., Wieringa, B. M., Nager, W., Muller-Vahl, K. R., Dengler, R., \& Munte, T. F. (2002). Excessive action monitoring in Tourette syndrome. J.Neurol., 249(8), 961-966. 
Kadesjo, B., \& Gillberg, C. (2000). Tourette's disorder: epidemiology and comorbidity in primary school children. J Am Acad Child Adolesc Psychiatry, 39(5), 548-555.

Karno, M., Golding, J. M., Sorenson, S. B., \& Burnam, M. A. (1988). The epidemiology of obsessive-compulsive disorder in five US communities. Arch Gen Psychiatry, 45(12), 1094-1099.

Katayama, K., Yamada, K., Ornthanalai, V. G., Inoue, T., Ota, M., Murphy, N. P., et al. (2010). Slitrk1-deficient mice display elevated anxiety-like behavior and noradrenergic abnormalities. Mol Psychiatry, 15(2), 177-184.

Keen-Kim, D., \& Freimer, N. B. (2006). Genetics and epidemiology of Tourette syndrome. J Child Neurol, 21(8), 665-671.

King, R. A., \& Scahill, L. (2001). Emotional and behavioral difficulties associated with Tourette syndrome. Adv Neurol, 85, 79-88.

Kutas, M., \& Donchin, E. (1980). Preparation to respond as manifested by movement-related brain potentials. Brain Research, 202(1), 95-115.

Lassen, N. A., \& Ingvar, D. H. (1990). Brain regions involved in voluntary movements as revealed by radioisotopic mapping of CBF or CMR-glucose changes. Rev Neurol (Paris), 146(10), 620-625.

Lavenstein, B. L. (2003). Treatment approaches for children with Tourette's syndrome. Curr Neurol Neurosci Rep, 3(2), 143-148.

Lavoie, M. E., Imbriglio, T. V., Baltazar, L., Thibault, G., Stip, E., \& O'Connor, K. P. (2008). Evaluation and treatment of Tourette syndrome: An integrated behavioral and neurocognitive approach focusing on motor processing. Journal of the International Neuropsychological Society, 14(Suppl. 1), 273.

Lavoie, M. E., Imbriglio, T. V., Stip, E., \& O'Connor, K. P. (2011). Neurocognitive changes following cognitive-behavioral treatment in the Tourette syndrome and chronic tic disorder. International Journal of Cognitive Psychotherapy, 4(2), 34-50.

Lavoie, M. E., Thibault, G., Stip, E., \& O'Connor, K. P. (2007). Memory and executive functions in adults with Gilles de la Tourette syndrome and chronic tic disorder. Cognit Neuropsychiatry, 12(2), 165-181.

Leckman, J. F. (2002). Tourette's syndrome. Lancet, 360(9345), 1577-1586.

Leckman, J. F., Bloch, M. H., Scahill, L., \& King, R. A. (2006). Tourette syndrome: the self under siege. J Child Neurol, 21(8), 642-649.

Leckman, J. F., Peterson, B. S., Anderson, G. M., Arnsten, A. F., Pauls, D. L., \& Cohen, D. J. (1997). Pathogenesis of Tourette's syndrome. Journal of child psychology and psychiatry, and allied disciplines, 38(1), 119-142.

Leckman, J. F., Zhang, H., Vitale, A., Lahnin, F., Lynch, K., Bondi, C., et al. (1998). Course of tic severity in Tourette syndrome: the first two decades. Pediatrics, 102(1 Pt 1), 14-19.

Leclerc, J., Forget, J., \& O'Connor, K. P. (2008). Quand le corps fait à sa tête - Le syndrome de Gilles de la Tourette. Montréal: Multimondes.

Logothetis, N. K. (2008). What we can do and what we cannot do with fMRI. Nature, 453(7197), 869-878.

Mahone, E. M., Koth, C. W., Cutting, L., Singer, H. S., \& Denckla, M. B. (2001). Executive function in fluency and recall measures among children with Tourette syndrome or ADHD. J.Int.Neuropsychol.Soc., 7(1), 102-111.

Malloy, P., Rasmussen, S., Braden, W., \& Haier, R. J. (1989). Topographic evoked potential mapping in obsessive-compulsive disorder: evidence of frontal lobe dysfunction. Psychiatry Res, 28(1), 63-71. 
Marsh, R., Alexander, G. M., Packard, M. G., Zhu, H., \& Peterson, B. S. (2005). Perceptualmotor skill learning in Gilles de la Tourette syndrome. Evidence for multiple procedural learning and memory systems. Neuropsychologia, 43(10), 1456-1465.

Marsh, R., Zhu, H., Wang, Z., Skudlarski, P., \& Peterson, B. S. (2007). A developmental fMRI study of self-regulatory control in Tourette's syndrome. Am J Psychiatry, 164(6), 955966.

Menzies, L., Chamberlain, S. R., Laird, A. R., Thelen, S. M., Sahakian, B. J., \& Bullmore, E. T. (2008). Integrating evidence from neuroimaging and neuropsychological studies of obsessive-compulsive disorder: the orbitofronto-striatal model revisited. Neurosci Biobehav Rev, 32(3), 525-549.

Miller, E. K., \& Cohen, J. D. (2001). An integrative theory of prefrontal cortex function. Annu Rev Neurosci, 24, 167-202.

Mink, J. W. (2001). Basal ganglia dysfunction in Tourette's syndrome: a new hypothesis. Pediatr Neurol, 25(3), 190-198.

Miyata, A., Matsunaga, H., Kiriike, N., Iwasaki, Y., Takei, Y., \& Yamagami, S. (1998). Eventrelated potentials in patients with obsessive-compulsive disorder. Psychiatry Clin Neurosci, 52(5), 513-518.

Morault, P., Guillem, F., Bourgeois, M., \& Paty, J. (1998). Improvement predictors in obsessive-compulsive disorder. An event-related potential study. Psychiatry Res, 81(1), 87-96.

Morault, P. M., Bourgeois, M., Laville, J., Bensch, C., \& Paty, J. (1997). Psychophysiological and clinical value of event-related potentials in obsessive-compulsive disorder. Biol Psychiatry, 42(1), 46-56.

Murray, E. A., O'Doherty, J. P., \& Schoenbaum, G. (2007). What we know and do not know about the functions of the orbitofrontal cortex after 20 years of cross-species studies. J Neurosci, 27(31), 8166-8169.

O'Connor, K. P. (2002). A cognitive-behavioral/psychophysiological model of tic disorders. Behaviour Research and Therapy, 40, 1113-1142.

O'Connor, K. P. (2005). Cognitive-behavioral management of tic disorders. . New York: John Wiley.

O'Connor, K. P. (2005). Testing the cognitive-psychophysiological model: validation of a style of planning action (STOP) as a discriminator between tic disorder, obsessivecompulsive disorder and generalized anxiety. In Cognitive-Behavioral Management of tic disorders (pp. 65-73.). Chichester: John-Wiley and Sons.

O'Connor, K. P., Brault, M., Robillard, S., Loiselle, J., Borgeat, F., \& Stip, E. (2001). Evaluation of a cognitive-behavioural program for the management of chronic tic and habit disorders. Behav.Res.Ther., 39(6), 667-681.

O'Connor, K. P., Laverdure, A., Taillon, A., Stip, E., Borgeat, F., \& Lavoie, M. (2009). Cognitive behavioral management of Tourette's syndrome and chronic tic disorder in medicated and unmedicated samples. Behav Res Ther, 47(12), 1090-1095.

O'Connor, K. P., Lavoie, M. E., Robert, M., Stip, E., \& Borgeat, F. (2005). Brain-behavior relations during motor processing in chronic tic and habit disorder. Cognitive and behavioral neurology 18(2), 79-88.

O'Connor, K. P., Lavoie, M. E., Stip, E., Borgeat, F., \& Laverdure, A. (2008). Cognitivebehaviour therapy and skilled motor performance in adults with chronic tic disorder. Neuropsychol Rehabil, 18(1), 45-64.

Oades, R. D., Dittmann-Balcar, A., Schepker, R., Eggers, C., \& Zerbin, D. (1996). Auditory event-related potentials (ERPs) and mismatch negativity (MMN) in healthy 
children and those with attention-deficit or tourette/tic symptoms. Biological Psychology, 43(2), 163-185.

Ozonoff, S., \& Jensen, J. (1999). Brief report: specific executive function profiles in three neurodevelopmental disorders. J.Autism Dev.Disord., 29(2), 171-177.

Ozonoff, S., Strayer, D. L., McMahon, W. M., \& Filloux, F. (1998). Inhibitory deficits in Tourette syndrome: a function of comorbidity and symptom severity. J.Child Psychol.Psychiatry, 39(8), 1109-1118.

Pappert, E. J., Goetz, C. G., Louis, E. D., Blasucci, L., \& Leurgans, S. (2003). Objective assessments of longitudinal outcome in Gilles de la Tourette's syndrome. Neurology, 61(7), 936-940.

Pauls, D. L. (1992). The genetics of obsessive compulsive disorder and Gilles de la Tourette's syndrome. Psychiatr Clin North Am, 15(4), 759-766.

Pauls, D. L. (2003). An update on the genetics of Gilles de la Tourette syndrome. J Psychosom Res, 55(1), 7-12.

Pauls, D. L., Alsobrook, J. P., 2nd, Goodman, W., Rasmussen, S., \& Leckman, J. F. (1995). A family study of obsessive-compulsive disorder. Am J Psychiatry, 152(1), 76-84.

Pauls, D. L., Towbin, K. E., Leckman, J. F., Zahner, G. E., \& Cohen, D. J. (1986). Gilles de la Tourette's syndrome and obsessive-compulsive disorder. Evidence supporting a genetic relationship. Arch Gen Psychiatry, 43(12), 1180-1182.

Peterson, B., Riddle, M. A., Cohen, D. J., Katz, L. D., Smith, J. C., Hardin, M. T., et al. (1993). Reduced basal ganglia volumes in Tourette's syndrome using three-dimensional reconstruction techniques from magnetic resonance images. Neurology, 43(5), 941-949.

Peterson, B. S. (2001). Neuroimaging studies of Tourette syndrome: a decade of progress. Adv.Neurol., 85, 179-196.

Peterson, B. S., Choi, H. A., Hao, X., Amat, J. A., Zhu, H., Whiteman, R., et al. (2007). Morphologic features of the amygdala and hippocampus in children and adults with Tourette syndrome. Arch Gen Psychiatry, 64(11), 1281-1291.

Peterson, B. S., Leckman, J. F., Tucker, D., Scahill, L., Staib, L., Zhang, H., et al. (2000). Preliminary findings of antistreptococcal antibody titers and basal ganglia volumes in tic, obsessive-compulsive, and attention deficit/hyperactivity disorders. Arch Gen Psychiatry, 57(4), 364-372.

Peterson, B. S., Skudlarski, P., Anderson, A. W., Zhang, H., Gatenby, J. C., Lacadie, C. M., et al. (1998). A functional magnetic resonance imaging study of tic suppression in Tourette syndrome. Arch.Gen.Psychiatry, 55(4), 326-333.

Peterson, B. S., Staib, L., Scahill, L., Zhang, H., Anderson, C., Leckman, J. F., et al. (2001). Regional brain and ventricular volumes in Tourette syndrome. Archives of General Psychiatry, 58(5), 427-440.

Piacentini, J., Woods, D. W., Scahill, L., Wilhelm, S., Peterson, A. L., Chang, S., et al. (2010). Behavior therapy for children with Tourette disorder: a randomized controlled trial. Jama, 303(19), 1929-1937.

Price, R. A., Leckman, J. F., Pauls, D. L., Cohen, D. J., \& Kidd, K. K. (1986). Gilles de la Tourette's syndrome: tics and central nervous system stimulants in twins and nontwins. Neurology, 36(2), 232-237.

Pringsheim, T., \& Marras, C. (2009). Pimozide for tics in Tourette's syndrome. Cochrane Database Syst Rev(2), CD006996.

Rankins, D., Bradshaw, J. L., \& Georgiou-Karistianis, N. (2006). The semantic Simon effect in Tourette's syndrome and obsessive-compulsive disorder. Brain Cogn, 61(3), 225-234. 
Ray Li, H.-L., Hsu, Y.-P., Wang, H.-S., \& Ko, N.-C. (2006). Motor Response Inhibition in Children With Tourette's Disorder. The Journal of Neuropsychiatry and Clinical Neurosciences, 18(3), 417.

Rektor, I. (2002). Scalp-recorded Bereitschaftspotential is the result of the activity of cortical and subcortical generators--a hypothesis. Clinical Neurophysiology, 113(12), 1998-2005.

Rektor, I., Kaiiovsky, P., Bares, M., Brazdil, M., Streitova, H., Klajblova, H., et al. (2003). A SEEG study of ERP in motor and premotor cortices and in the basal ganglia. Clinical Neurophysiology, 114(3), 463-471.

Requin, J., \& Riehle, A. (1995). Neural correlates of partial transmission of sensorimotor information in the cerebral cortex. Acta Psychologica, 90(1-3), 81-95.

Robertson, M. M. (2003). Diagnosing Tourette syndrome: is it a common disorder? J Psychosom Res, 55(1), 3-6.

Robertson, M. M., \& Stern, J. S. (2000). Gilles de la Tourette syndrome: symptomatic treatment based on evidence. Eur Child Adolesc Psychiatry, 9 Suppl 1, I60-75.

Roth, R. M., Baribeau, J., Milovan, D., O'Connor, K., \& Todorov, C. (2004). Procedural and declarative memory in obsessive-compulsive disorder. J Int Neuropsychol Soc, 10(5), 647-654.

Rothenberger, A. K., S. (1982). Bereitschaftpotential in children with multiple tics and Gilles de la Tourette syndrome. In A. Rothenberger. (Ed.), Event-Related Potentials in children (pp. 257-270). Amsterdam: Elsevier Biomedical Press.

Rothenberger, A. K., S., Schenk, G.K., Zerbin, D. Voss, M. (1986). Movement-Related potentials in children with hypermotoric behaviour. In R. Z. W.C. McCallum., F.Denoth. (Ed.), Cerebral Psychophysiology: studies in event-related potentials (Vol. EEG suppl 38, pp. 496499.). Amsterdam: Elsevier Science publishers, B.V. (Biomedical division).

Sanz, M., Molina, V., Martin-Loeches, M., Calcedo, A., \& Rubia, F. J. (2001). Auditory P300 event related potential and serotonin reuptake inhibitor treatment in obsessivecompulsive disorder patients. Psychiatry Res, 101(1), 75-81.

Sarason, I. G., Johnson, J. H., \& Siegel, J. M. (1978). Assessing the impact of life changes: development of the Life Experiences Survey. J Consult Clin Psychol, 46(5), 932-946.

Savage, C. R., Weilburg, J. B., Duffy, F. H., Baer, L., Shera, D. M., \& Jenike, M. A. (1994). Low-level sensory processing in obsessive-compulsive disorder: an evoked potential study. Biol Psychiatry, 35(4), 247-252.

Saxena, S., Brody, A. L., Schwartz, J. M., \& Baxter, L. R. (1998). Neuroimaging and frontalsubcortical circuitry in obsessive-compulsive disorder. Br J Psychiatry Suppl(35), 26-37.

Scahill, L., Leckman, J. F., Schultz, R. T., Katsovich, L., \& Peterson, B. S. (2003). A placebocontrolled trial of risperidone in Tourette syndrome. Neurology, 60(7), 1130-1135.

Scahill, L., Sukhodolsky, D. G., Williams, S. K., \& Leckman, J. F. (2005). Public health significance of tic disorders in children and adolescents. Adv Neurol, 96, 240-248.

Scharf, J. M., Moorjani, P., Fagerness, J., Platko, J. V., Illmann, C., Galloway, B., et al. (2008). Lack of association between SLITRK1var321 and Tourette syndrome in a large family-based sample. Neurology, 70(16 Pt 2), 1495-1496.

Schuerholz, L. J., Baumgardner, T. L., Singer, H. S., Reiss, A. L., \& Denckla, M. B. (1996). Neuropsychological status of children with Tourette's syndrome with and without attention deficit hyperactivity disorder. Neurology, 46(4), 958-965.

Serrien, D. J., Nirkko, A. C., Loher, T. J., Lovblad, K. O., Burgunder, J. M., \& Wiesendanger, M. (2002). Movement control of manipulative tasks in patients with Gilles de la Tourette syndrome. Brain, 125(Pt 2), 290-300. 
Shapiro, A. K., \& Shapiro, E. (1992). Evaluation of the reported association of obsessivecompulsive symptoms or disorder with Tourette's disorder. Compr Psychiatry, 33(3), 152-165.

Shapiro, E., \& Shapiro, A. K. (1986). Semiology, nosology and criteria for tic disorders. Revue neurologique, 142(11), 824-832.

Sheppard, D. M., Bradshaw, J. L., Purcell, R., \& Pantelis, C. (1999). Tourette's and comorbid syndromes: obsessive compulsive and attention deficit hyperactivity disorder. A common etiology? Clin Psychol Rev, 19(5), 531-552.

Sowell, E. R., Kan, E., Yoshii, J., Thompson, P. M., Bansal, R., Xu, D., et al. (2008). Thinning of sensorimotor cortices in children with Tourette syndrome. Nat Neurosci, 11(6), 637-639.

Spessot, A. L., Plessen, K. J., \& Peterson, B. S. (2004). Neuroimaging of developmental psychopathologies: the importance of self-regulatory and neuroplastic processes in adolescence. Ann N Y Acad Sci, 1021, 86-104.

State, M. W. The genetics of Tourette disorder. Curr Opin Genet Dev, 21(3), 302-309.

Stephens, R. J., \& Sandor, P. (1999). Aggressive behaviour in children with Tourette syndrome and comorbid attention-deficit hyperactivity disorder and obsessivecompulsive disorder. Can J Psychiatry, 44(10), 1036-1042.

Stillman, A. A., Krsnik, Z., Sun, J., Rasin, M. R., State, M. W., Sestan, N., et al. (2009). Developmentally regulated and evolutionarily conserved expression of SLITRK1 in brain circuits implicated in Tourette syndrome. J Comp Neurol, 513(1), 21-37.

Stoetter, B., Braun, A. R., Randolph, C., Gernert, J., Carson, R. E., Herscovitch, P., et al. (1992). Functional neuroanatomy of Tourette syndrome. Limbic-motor interactions studied with FDG PET. Advances in neurology, 58, 213-226.

Sutherland, R. J., Kolb, B., Schoel, W. M., Whishaw, I. Q., \& Davies, D. (1982). Neuropsychological assessment of children and adults with Tourette syndrome: a comparison with learning disabilities and schizophrenia. Adv.Neurol., 35, 311-322.

Swain, J. E., Scahill, L., Lombroso, P. J., King, R. A., \& Leckman, J. F. (2007). Tourette syndrome and tic disorders: a decade of progress. J Am Acad Child Adolesc Psychiatry, 46(8), 947-968.

Thibault, G., Felezeu, M., O'Connor, K. P., Todorov, C., Stip, E., \& Lavoie, M. E. (2008). Influence of comorbid obsessive-compulsive symptoms on brain event-related potentials in Gilles de la Tourette syndrome. Prog Neuropsychopharmacol Biol Psychiatry, 32(3), 803-815.

Thibault, G., O'Connor, K. P., Stip, E., \& Lavoie, M. E. (2009). Electrophysiological manifestations of stimulus evaluation, response inhibition and motor processing in Tourette syndrome patients. Psychiatry Res, 167(3), 202-220.

Thibault, G., O'Connor, K. P., Stip, E., \& Lavoie, M. E. (2008). Electrophysiological manifestations of stimulus evaluation, response inhibition and motor processing in Tourette syndrome patients. Psychiatry Research. Psychiatry Research, doi:10.1016/j.psychres., 2008.2003.2021.

Thibert, A. L., Day, H. I., \& Sandor, P. (1995). Self-concept and self-consciousness in adults with Tourette syndrome. Can J Psychiatry, 40(1), 35-39.

Towey, J., Bruder, G., Hollander, E., Friedman, D., Erhan, H., Liebowitz, M., et al. (1990). Endogenous event-related potentials in obsessive-compulsive disorder. Biol Psychiatry, 28(2), 92-98. 
Towey, J., Bruder, G., Tenke, C., Leite, P., DeCaria, C., Friedman, D., et al. (1993). Eventrelated potential and clinical correlates of neurodysfunction in obsessivecompulsive disorder. Psychiatry Res, 49(2), 167-181.

Towey, J. P., Tenke, C. E., Bruder, G. E., Leite, P., Friedman, D., Liebowitz, M., et al. (1994). Brain event-related potential correlates of overfocused attention in obsessivecompulsive disorder. Psychophysiology, 31(6), 535-543.

Trevena, J. A., \& Miller, J. (2002). Cortical movement preparation before and after a conscious decision to move. Conscious Cogn, 11(2), 162-190; discussion 314-125.

Van de Wetering, B. J., Martens, C. M., Fortgens, C., Slaets, J. P., \& van Woerkom, T. C. (1985). Late components of the auditory evoked potentials in Gilles de la Tourette syndrome. Clinical neurology and neurosurgery, 87(3), 181-186.

van Woerkom, T. C., Fortgens, C., Rompel-Martens, C. M., \& Van de Wetering, B. J. (1988). Auditory event-related potentials in adult patients with Gilles de la Tourette's syndrome in the oddball paradigm. Electroencephalography and Clinical Neurophysiology, 71(6), 443-449.

van Woerkom, T. C., Roos, R. A., \& van Dijk, J. G. (1994). Altered attentional processing of background stimuli in Gilles de la Tourette syndrome: a study in auditory eventrelated potentials evoked in an oddball paradigm. Acta Neurol.Scand., 90(2), 116-123.

Yeates, K. O., Bornstein, R. A. (1994). Attention deficit disorder and neuropsychological functioning in children with Tourette's syndrome. Neuropsychology, 8, 65-74.

Zohar, A. H., Ratzoni, G., Pauls, D. L., Apter, A., Bleich, A., Kron, S., et al. (1992). An epidemiological study of obsessive-compulsive disorder and related disorders in Israeli adolescents. J Am Acad Child Adolesc Psychiatry, 31(6), 1057-1061. 


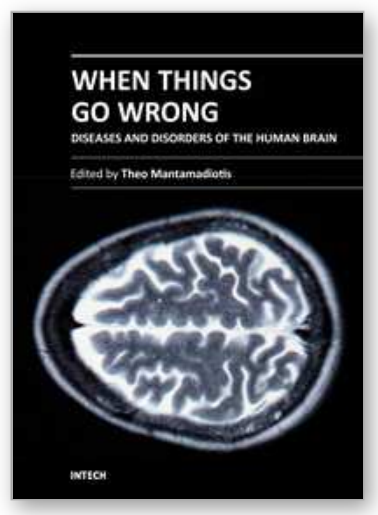

\author{
When Things Go Wrong - Diseases and Disorders of the Human \\ Brain \\ Edited by Dr. Theo Mantamadiotis
}

ISBN 978-953-51-0111-6

Hard cover, 238 pages

Publisher InTech

Published online 29, February, 2012

Published in print edition February, 2012

In this book we have experts writing on various neuroscience topics ranging from mental illness, syndromes, compulsive disorders, brain cancer and advances in therapies and imaging techniques. Although diverse, the topics provide an overview of an array of diseases and their underlying causes, as well as advances in the treatment of these ailments. This book includes three chapters dedicated to neurodegenerative diseases, undoubtedly a group of diseases of huge socio-economic importance due to the number of people currently suffering from this type of disease but also the prediction of a huge increase in the number of people becoming afflicted. The book also includes a chapter on the molecular and cellular aspects of brain cancer, a disease which is still amongst the least treatable of cancers.

\title{
How to reference
}

In order to correctly reference this scholarly work, feel free to copy and paste the following:

Marc E. Lavoie and Kieron P. O'Connor (2012). Neurocognitive Aspects of Tourette Syndrome and Related Disorders, When Things Go Wrong - Diseases and Disorders of the Human Brain, Dr. Theo Mantamadiotis (Ed.), ISBN: 978-953-51-0111-6, InTech, Available from: http://www.intechopen.com/books/when-things-gowrong-diseases-and-disorders-of-the-human-brain/neurocognitive-aspects-of-tourette-syndrome-and-relateddisorders

\section{INTECH}

open science | open minds

\author{
InTech Europe \\ University Campus STeP Ri \\ Slavka Krautzeka 83/A \\ 51000 Rijeka, Croatia \\ Phone: +385 (51) 770447 \\ Fax: +385 (51) 686166 \\ www.intechopen.com
}

\author{
InTech China \\ Unit 405, Office Block, Hotel Equatorial Shanghai \\ No.65, Yan An Road (West), Shanghai, 200040, China \\ 中国上海市延安西路65号上海国际贵都大饭店办公楼 405 单元 \\ Phone: +86-21-62489820 \\ Fax: $+86-21-62489821$
}


(C) 2012 The Author(s). Licensee IntechOpen. This is an open access article distributed under the terms of the Creative Commons Attribution 3.0 License, which permits unrestricted use, distribution, and reproduction in any medium, provided the original work is properly cited. 